\title{
A "new" design requirement: the mitigation of the progressive collapse of buildings under exceptional loading
}

\author{
Jaspart JP * and Demonceau JF
}

Department ArGEnCo, Liège University, Belgium.

Corresponding Author: jean-pierre.jaspart@ulg.ac.be

\begin{abstract}
Recent events such as natural catastrophes or terrorism attacks have highlighted the necessity to ensure the structural integrity of buildings under an exceptional event. According to the Eurocodes and some different other national design codes, the structural integrity of civil engineering structures should be ensured through appropriate measures but, in most cases, no precise practical guidelines on how to achieve this goal are provided. At Liège University, the robustness of building frames is investigated with the final objective to propose design requirements to mitigate the risk of progressive collapse considering the conventional scenario "loss of a column" further to an unspecified event. In particular, a complete analytical procedure has been developed for the verification of the robustness of steel or composite plane frames. For sake of simplicity, these first works have been based on the assumption that the dynamic effects linked to the column loss were limited and could therefore be neglected. More recently, complementary works have been carried out with the objective to address the dynamic effects. Besides that, the extension of the static procedure to actual 3D frames is under investigation in Liège. The present paper gives a global overview of the ongoing researches in the field of robustness at Liège University; in particular, the global strategy to derive design requirements is detailed.
\end{abstract}

Key words: Robustness, Exceptional loading, Loss of column.

\section{Adopted strategy}

The studies performed at Liège University in the field of "robustness of structures" are mainly dedicated to the exceptional scenario "loss of a column" in a steel or steel-concrete composite building structure. The main objective is to derive guidelines for an appropriate design of the structure for the considered scenario.

To achieve this goal, simplified analytical procedures are developed to predict the response of the structure further to a column loss; as an outcome, the way on how each structural parameter influences the structural behaviour may be described. The present section describes the global research strategy adopted by the authors.

The loss of a column can be associated to different types of exceptional events: explosion, impact of a vehicle, fire... Under many of these exceptional actions, dynamic effects may play an important role. However, it is first assumed that the column loss does not induce dynamic effects; so, the investigations of the structural response may be founded on static approaches.

A building structure losing a column can be divided in two main parts, as illustrated in Figure 1:

- The directly affected part which represents the part of the building which is directly affected by the column loss, i.e. the beams, the columns and the beam-to-column joints which are just above the failing column and;

- The indirectly affected part which includes the rest of the structure. The indirectly affected part is affected by the loads developing within the directly affected part; but obviously, these forces are themselves influenced by the response of the indirectly affected part. 


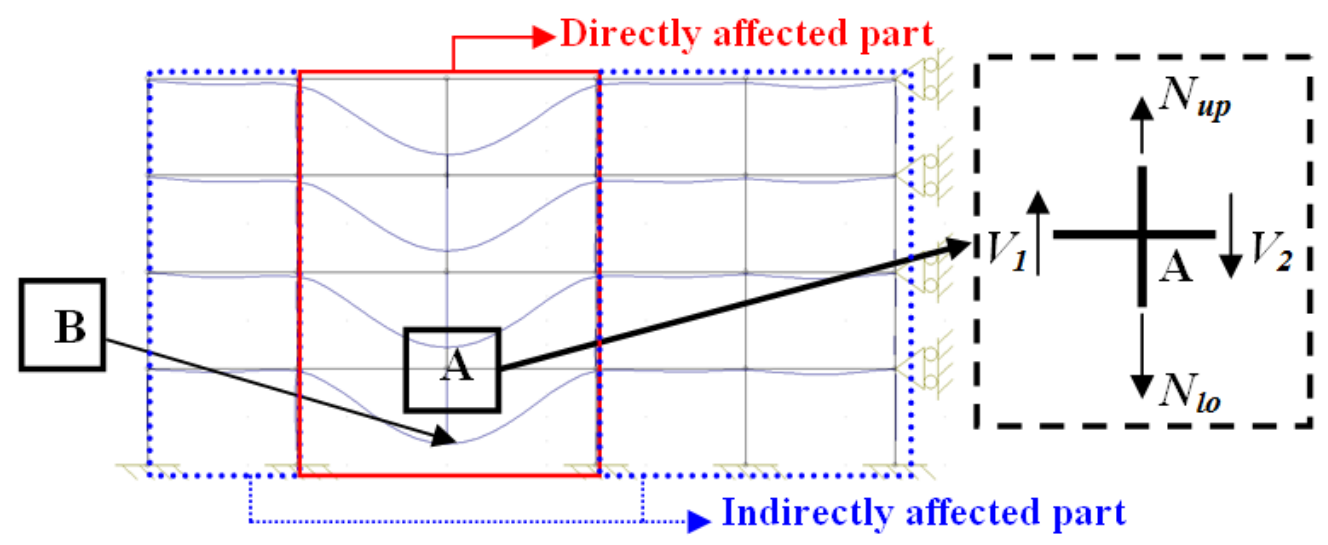

Fig 1. Representation of a frame losing a column and main definitions.

In Figure 2, the curve representing the static evolution of the vertical displacement $\Delta_{A}$ according to the normal load $N_{l o}$ in the failing column (see Figure 1) is illustrated:

- From point (1) to (2) (Phase 1), the design loads are progressively applied, i.e the "conventional" loading is applied to the structure; so, $N_{l o}$ progressively decreases $\left(N_{l o}\right.$ becomes negative as the column " $\mathrm{AB}$ " is subjected to compression) while $\Delta_{A}$ remains approximately equal to 0 during this phase. It is assumed that no yielding appears in the investigated frame during this phase, i.e. the frame remains fully elastic.

- From point (2) to (5), the column is progressively removed. Indeed, from point (2), the compression in column " $\mathrm{AB}$ " $N_{l o}$ decreases until it reaches a value equal to 0 at point (5) where the column is considered as fully destroyed. So, in this zone, the absolute value of $N_{l o}$ progressively decreases while the value of $\Delta_{A}$ increases. This part of the graph is divided in two phases as represented in Figure 2:

- From point (2) to (4) (Phase 2): during this phase, the directly affected part passes from a fully elastic behaviour (from point (2) to (3)) to a global plastic mechanism. In (3), the first plastic hinges appear in the directly affected part.

- From point (4) to (5) (Phase 3): during this phase, high deformations of the directly affected part are observed and second order effects play an important role. In particular, significant catenary actions develop in the bottom beams of the directly affected part.

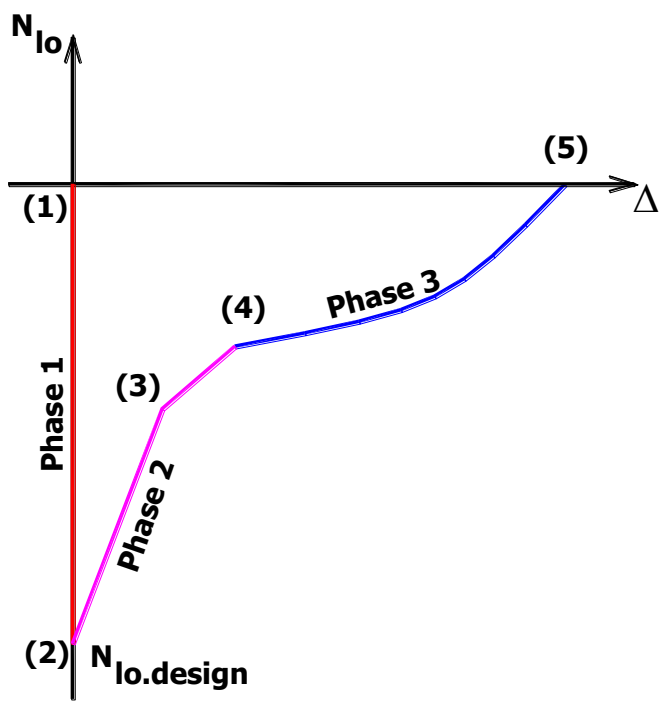

Fig 2. Evolution of $N_{l o}$ according to the vertical displacement at the top of the lost column. 
It is only possible to reach point (5) if:

- Resistance of the directly affected part is appropriate;

- The loads which are reported from the directly affected part to the indirectly affected part do not induce the collapse of elements in the latter (for instance, buckling of columns or development of a global plastic mechanism in the indirectly affected part);

- The different structural elements have a sufficient ductility to reach the vertical displacement corresponding to point (5).

This global approach was first developed for steel and composite structures but may be applied to other typologies of structures, as given in Table 1.

Table 1. Steps to be crossed to derive design recommendations: (I: initiated, D: developed, TBD: to be developed).

\begin{tabular}{|c|c|c|c|c|c|}
\hline Design recommendations & TBD & TBD & TBD & TBD & TBD \\
\hline \hline $\begin{array}{c}\text { Dynamic effects/type of } \\
\text { exceptional actions }\end{array}$ & I & TBD & TBD & TBD & TBD \\
\hline 3D behavior & I & I & TBD & TBD & TBD \\
\hline 2D behavior & D & D & TBD & TBD & TBD \\
\hline Global approach & $\begin{array}{c}\text { Steel } \\
\text { structures }\end{array}$ & $\begin{array}{c}\text { Composite } \\
\text { structures }\end{array}$ & $\begin{array}{c}\text { Concrete } \\
\text { structures }\end{array}$ & $\begin{array}{c}\text { Timber } \\
\text { structures }\end{array}$ & $\begin{array}{c}\text { Masonry } \\
\text { structures }\end{array}$ \\
\hline$/$
\end{tabular}

In a first step, simplified analytical methods were developed to predict the response of 2D steel and composite frames further to the loss of a column with no dynamic effects; the latter are summarised in section 2. Then, based on this first step, studies were initiated to take the 3D structural response and the dynamic effects into account; these two aspects are respectively addressed in Section 3 and Section 4. The final objective is to progressively complete Table 1 with " $\mathrm{D}$ " indexes, what means that design recommendations would have been derived for most typologies of structures, with a similar global approach.

\section{Static behaviour of 2D frames further to a column loss}

Luu (2008) has studied the static response of 2D frames further to a column loss during Phase 1 and 2 (Figure 2), while Demonceau (2008) concentrates on Phase 3 in which catenary effects develop. The adopted strategy to study Phase 3 is presented in Figure 3:

- Step 1: an experimental test is carried out in Liège on a substructure with the aim to simulate the loss of a column in a composite building frame;

- Step 2: analytical and numerical FEM tools are validated through comparisons with the experimental results;

- Step 3: parametric studies based on the use of the models validated at step 2 are carried out; the objective is to identify the parameters influencing the frame response during Phase 3;

- Step 4: a simplified analytical method is developed with due account of the parameters identified at step 3 and validated through comparisons with the experimental test results of step1.

In the present paper, part of the research works performed within steps 1 (Section 2.1) and 4 (Section 2.2) are reflected. More information is available in (Demonceau, 2008, 2010) 


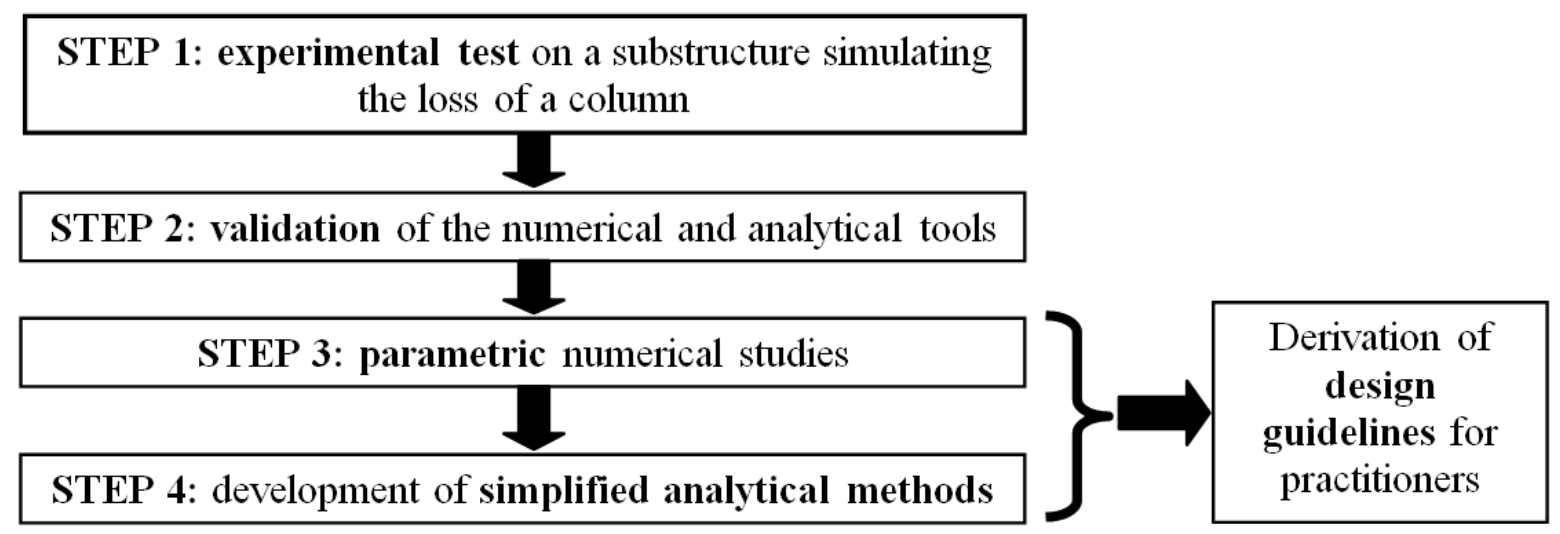

Fig 3. Strategy followed to investigate Phase 3.

\subsection{Experimental test on a substructure simulating the loss of a column}

A test on a composite substructure has been performed to simulate the loss of a column. The main objective of the test was to observe the development of catenary actions within a frame and the effect of these actions on the behaviour of the semi-rigid and partial-strength composite beam-to-column joints. Indeed these joints are initially designed and loaded in bending, but have progressively to support tensile loads as a result of the development of membrane tying forces in the beams.

To define the substructure properties, an "actual" composite building was first designed (Demonceau, 2008) according to Eurocode 4, so under "normal" loading conditions. As it was not possible to test a full 2-D actual composite frame within the project, a substructure was extracted from the actual frame (Demonceau, 2008); it was chosen so as to respect the dimensions of the testing floor in the laboratory but also to exhibit a similar behaviour than the one in the actual frame.

The tested substructure is presented in Figure 4. As illustrated, horizontal jacks were placed at each end of the specimen so as to simulate the lateral restraints brought by the indirectly affected part of actual building when catenary actions develop.

A specific loading history was followed during the test. First, the vertical jack at the middle was locked and permanent loads were applied on the concrete slab with steel plates and concrete blocks ("normal" loading situation). Then, the vertical jack was unlocked and large displacements develop progressively at point A (Figure 4) until the force in the jack vanished (free spanning of $8 \mathrm{~m}$ ). Finally, a downward vertical displacement was imposed to the system above the impacted column and was then progressively increased until collapse. The "vertical load vs. vertical displacement at point A" curve is reported in Figure 5.
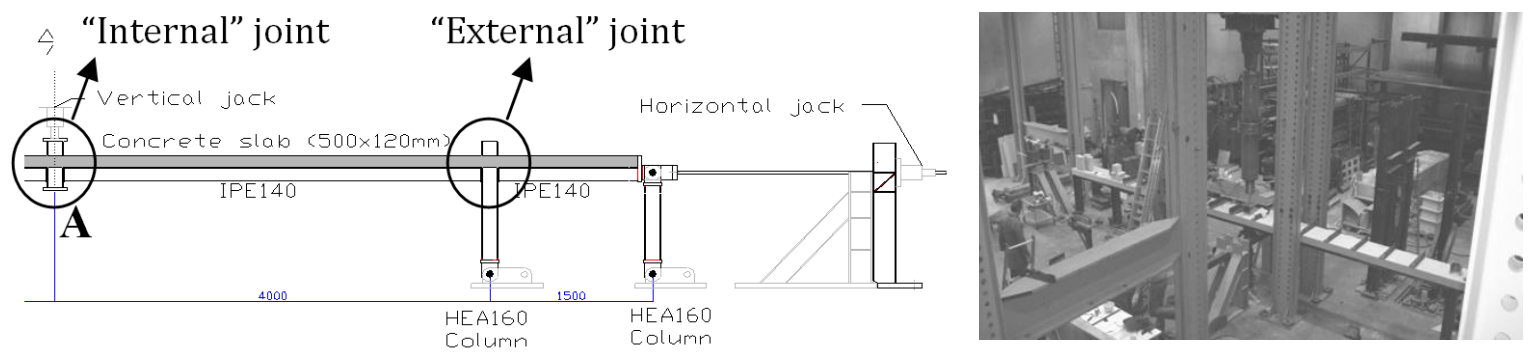

Fig 4. Tested substructure. 


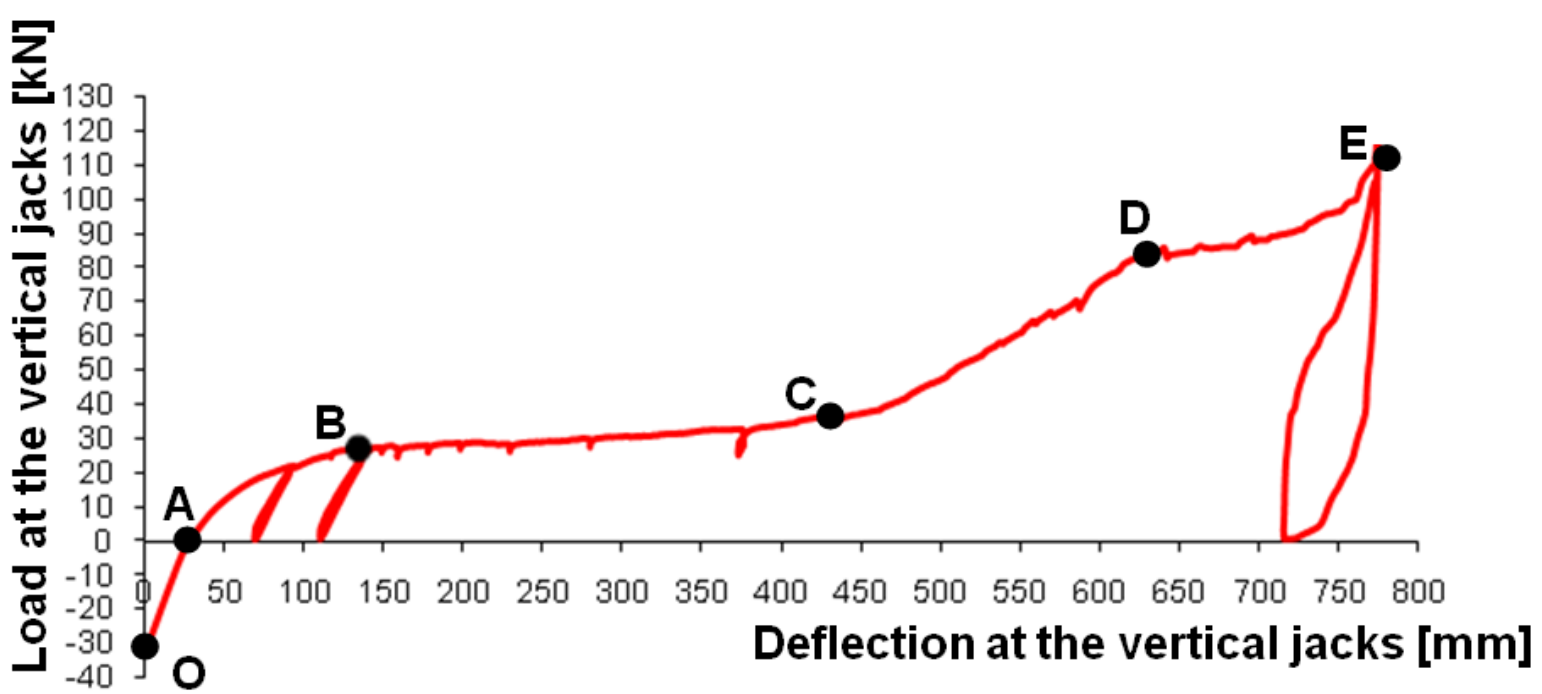

Fig 5. "Vertical load at the jack vs. vertical displacement at point $A$ " curve.

The first part of the test is represented by the segment "OA" of the curve presented in Figure 5 and which represents the evolution of the vertical load acting on the beams at the middle of the substructure according to the vertical displacement under the "impacted" column.

The vertical reaction in the lower column stub, before its removal, is equal to $-33,5 \mathrm{kN}$ (value of the load at point " 0 "). From Figure 5, it can be seen that the structure remains globally elastic when " $A$ " is reached.

Then, as previously explained, an increasing vertical displacement is progressively imposed until failure. During this stage, two "unloading-reloading" sequences are followed as illustrated in Figure 5.

From point "A" to "B" in Figure 5, the substructure yields progressively to finally form a beam plastic mechanism at point " $\mathrm{B}$ " (development of plastic hinges in the joints). At that moment, the cracks in the concrete slab at the external composite joints are pronounced and yielding of some steel components of the joints is observed (column web and beam flange in compression). Also, for the internal composite joint, a detachment of the end-plate and of the column flange is observed.

From point "B" to "C", a plateau develops, what means that the vertical displacements increase with a constant vertical load (equal to $30 \mathrm{kN}$ ). All along the plateau, the concrete cracks in the vicinity of the external composite joints continue to extend and yielding spreads further in the steel joint components. Besides that, the concrete in compression close to the internal composite joint crushes.

The horizontal jacks begin to be significantly activated at point "C" in Figure 5; at this point, membrane forces start to develop as confirmed by the shape of the global displacement curve (part "CD"). At point "D", the longitudinal rebars in the external composite joints suddenly fail; at that moment, the external joints work as steel ones. Yielding also affects the different components of the internal and external joints. At point "D", a loss of stiffness related to the failure of the rebars is observed; indeed, when these rebars fail, both flexural and tensile stiffness of the external joints decrease; but this not prevent the further development of catenary actions.

Indeed, it can be observed that the failure of the rebars does not lead to the failure of the substructure; after point " $\mathrm{D}$ ", the vertical load at the vertical jacks still increases with the imposed displacement (part "DE" of the curve in Figure 5). 
This is possible as long as the steel connection is able to support, alone, the membrane forces developed in the system. In addition, associated to the loss of the rebars, the vertical displacements are increasing with a low variation of the vertical loads. These additional vertical displacements induce an increase of the membrane forces. So, the steel connection working alone has at the end to be sufficiently resistant to support these additional membrane forces and sufficiently ductile to support the additional rotations associated to the vertical displacement. The capacity of the steel connections, working alone, to support significant membrane forces has been confirmed by tests on joints in isolation performed at Stuttgart University (Kuhlmann, 2008).

\subsection{Prediction of the frame response during Phase 3}

In Demonceau (2008), it was shown through numerical investigations that it is possible to extract a simplified substructure (see Figure 6) composed of the beams and the joints just above the lost column and likely represent accurately the actual global response of full frame during Phase 3. Accordingly, a simplified analytical method based on a rigid-plastic analysis has been developed to predict the response of the so-defined substructure. Also, as the deformations of the substructure are significant and influence its response, a second-order analysis has been conducted.

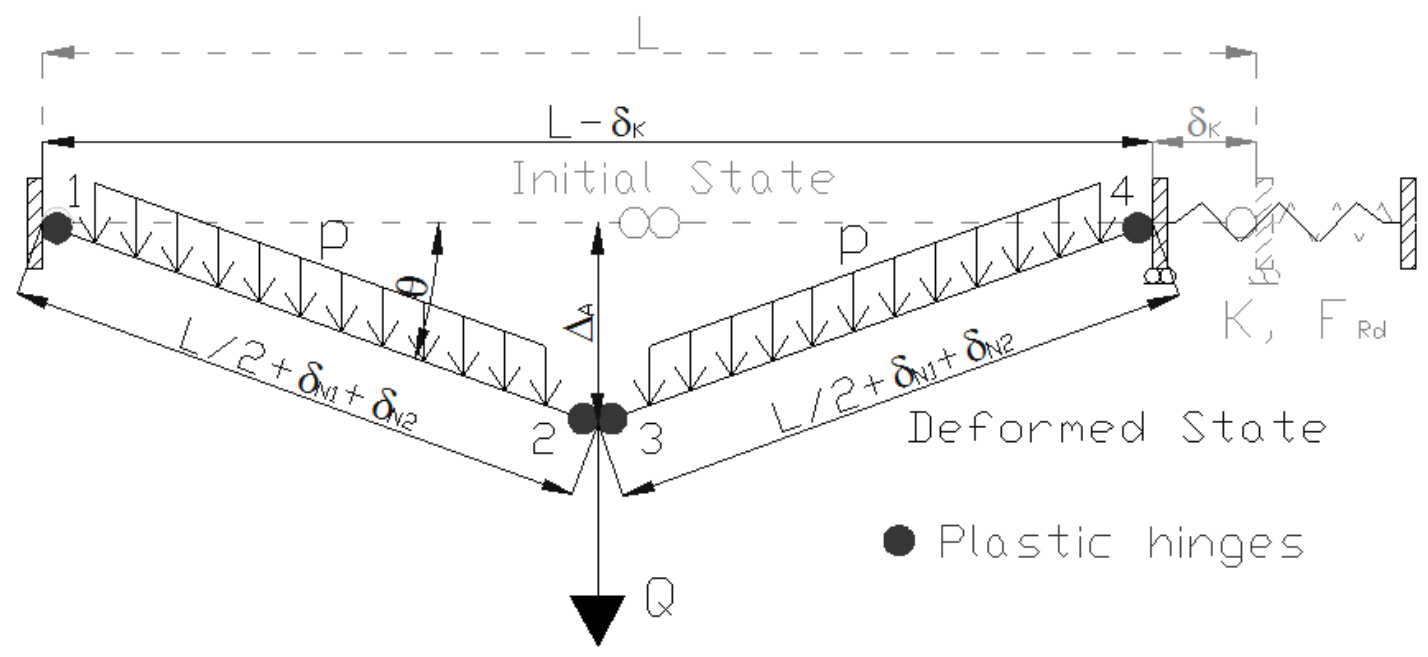

Fig 6. Substructure to be investigated.

The parameters taken into account in this process are illustrated in Figure 6:

- $\quad p$ is the (constant) uniformly distributed load applied on the storey modelled by the simplified substructure and the concentrated load

- $\quad Q$ is a concentrated load simulating the progressive loss of resistance of the column (= $N_{l o}-N_{\text {up }}$ - see Figure 1$)$;

- $\quad L$ is the total initial length of the substructure;

- $\quad \Delta_{A}$ is the vertical displacement at the concentrated load application point;

- $\quad \delta_{K}$ is the deformation of the horizontal spring simulating the lateral restraint provided by the indirectly affected part;

- $\quad \delta_{N 1}$ and $\delta_{N 2}$ are the plastic elongations at each plastic hinge;

- $\theta$ is the rotation in the plastic hinges at the beam extremities.

In addition, the axial and bending resistances at the plastic hinges $N_{R d 1}$ and $M_{R d 1}$ for plastic hinges 1 and 4 and $N_{R d 2}$ and $M_{R d 2}$ for plastic hinges 2 and 3 have also to be taken into account (it 
is assumed that the two plastic hinges 1 and 4 and the two plastic hinges 2 and 3 (see Figure 6) have respectively the same resistance curve for M-N interaction).

So as to be able to predict the response of the simplified substructure, the stiffness $K$ and the resistance $F_{R d}$ of the lateral restraint have to be known; these parameters depend of the properties of the indirectly affected part (see Figure 1). An analytical procedures have been defined to predict these characteristics (Luu, 2008; Huvelle, 2011).

Demonceau (2008) proposes an analytical expression for the $Q$ - $\Delta_{Q}$ curve characterising the response of the simplified substructure. As a validation, the results obtained with the latter have been compared to the results of the experimental test performed on the substructure (see previous section). In Figure 7, it is seen that a very good agreement is obtained between the analytical prediction and the experimental measurements. More details about the developed method are available in (Demonceau, 2008).

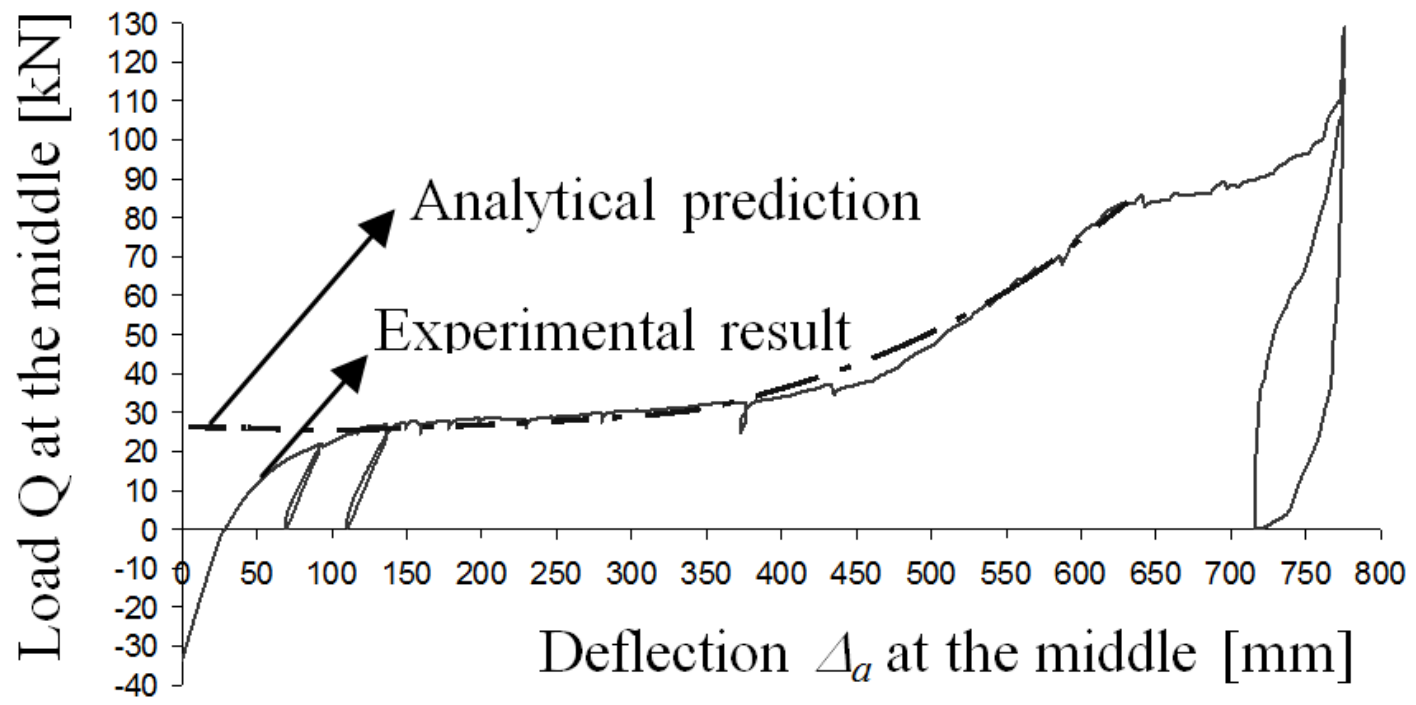

Fig 7. Comparison of analytical prediction vs. experimental results.

\section{Static behaviour of $3 \mathrm{~d}$ structures further to column loss}

Lemaire (2010) has investigated the behaviour of 3D structures made of steel beams and columns. Two different structures have been considered, with same dimensions and constitutive elements (see Figure 8); they just differ by the joint properties at the extremities of the secondary beams: pinned joints in Structure 1 and fully rigid joints in Structure 2.

For both cases, the column which is considered to be lost is the central one, as illustrated in Figure 8 (column "BX").
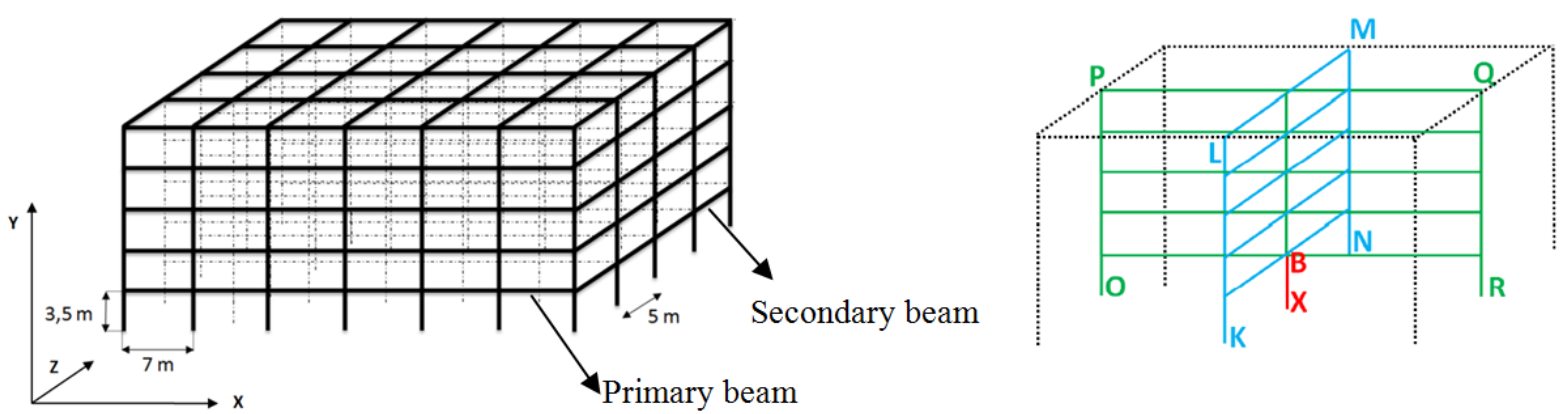

Fig 8. Investigated 3D structure. 
For each structure, a simplified substructure (see Figure 9) has been defined and extracted from the full 3D structure with the objective to check the possibility of this substructure to simulate with a sufficient accuracy the behaviour of the actual structure when significant membrane forces develop. The procedure followed for the definition of the substructure is the same as the one used for 2D frames (see Section 2 and (Demonceau, 2008)). This substructure is made of (i) four beams (two primary beams and two secondary beams) connected at the top of the failing column and of (ii) the joints at the extremities of these beams.

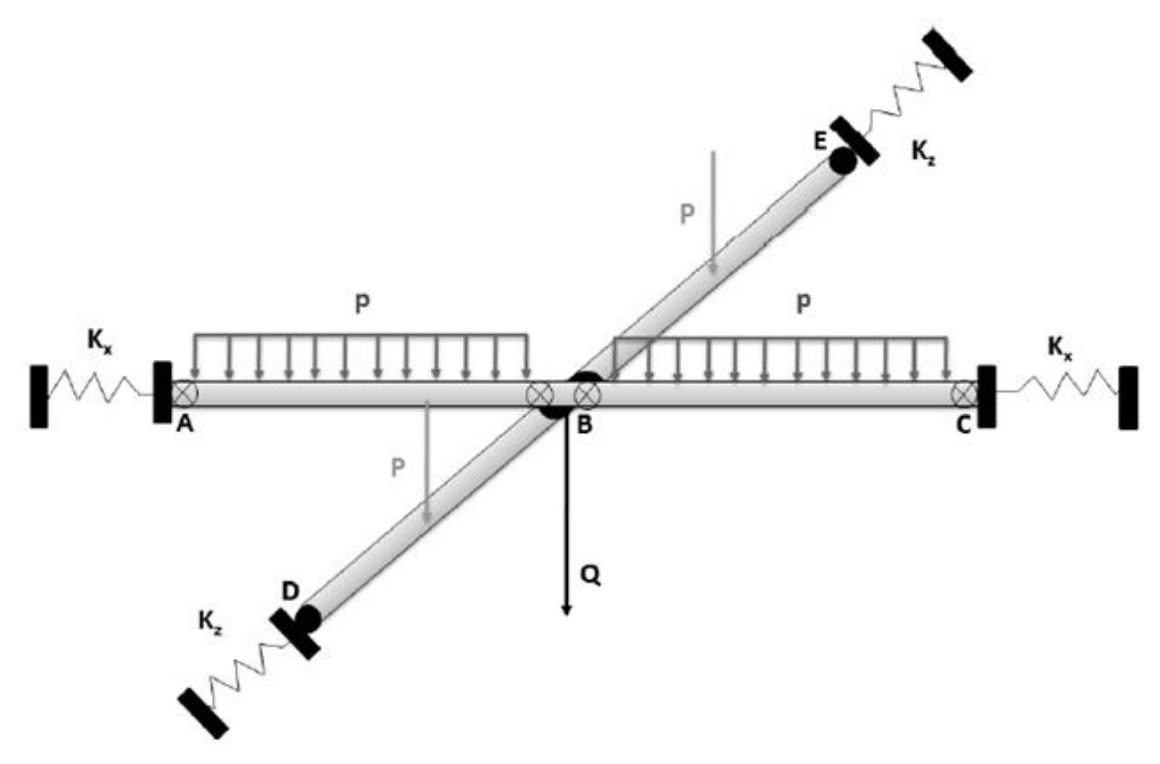

Fig 9. Substructure extracted from the 3D structure.

The influence of the rest of the structure (i.e. the part which is not directly affected by the column loss) is reflected by horizontal springs at the extremities of the so-defined substructure (see Figure 6), with appropriate stiffness $\left(K_{x}\right.$ and $\left.K_{z}\right)$.

In Figure 10, a comparison between the predictions obtained (i) through a numerical simulation of the global 3D structure losing a column and (ii) through a numerical simulation of the sodefined substructure is given for the two considered structures.
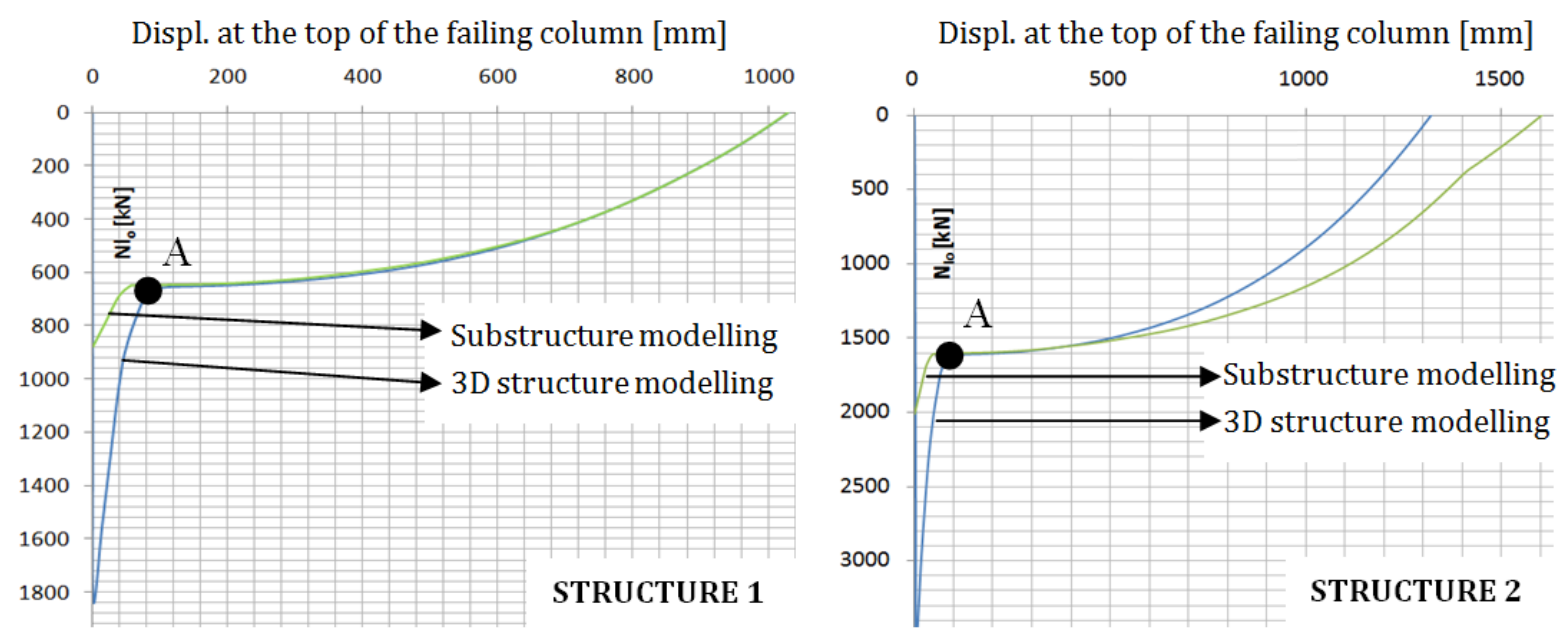

Fig 10. Comparisons between the results obtained through numerical simulations of the 3D structure and of the substructure.

The graphs given in Figure 10 represent the evolution of the axial load $N_{l o}$ in the failing column according to the vertical displacement at the top of this column. As the objective with the 
substructure is to predict the behaviour of the structure when significant membrane forces develop in the system, the predictions can only be compared from point A (see Figure 10), i.e. when a plastic mechanism is formed in the structure and significant vertical displacements are reached. In Figure 10, it can be observed that a very good agreement is obtained for Structure 1 while it is not the case for Structure 2.

This observation can be explained as follows. The loss of the column is reflected in the substructure modelling through the application of a concentrated load $Q$ (see Figure 9). In practice, this load $Q$ is equal to the difference between $N_{l o}$ and $N_{u p}$ (see Figure 1). For some structures, it was demonstrated through a parametrical study that, when significant membrane forces are developing in the directly affected beams, the value of $N_{u p}$ can be assumed as a constant (Luu, 2008). Accordingly, the variation of $Q$ vs. the deformation of the substructure reflects the variation of $N_{l o}$ in the global structure. It is the reason why, for some 2D structure, it is possible to reflect the actual behaviour of the 2D frame with the substructure. For Structure 1, $N_{u p}$ remains approximately constant after the formation of the plastic mechanism and thus the substructure approach is valid. But for Structure $2, N_{u p}$ is not remaining constant and, as a result, the variation of $Q$ according to the vertical displacement in the substructure modelling does not reflect the actual evolution of $N_{l o}$ in the 3D structure. The fact that $N_{u p}$ is no more constant when significant membrane forces are developing is linked to the fact that a redistribution of forces takes place between the storeys located above the lost column; this aspect, which has to be explicitly considered in the model, has not been analytically characterised yet but is currently investigated. If the variation of the normal force in the column just above the failing one is introduced in the substructure model, it may be seen that the results are in good agreement with those obtained from the study of the actual full 3D structure.

Lemaire (2010) has also demonstrated that the analytical method initially developed for 2D frames by Demonceau (2008) and able to predict the response of the "2D" substructure can be easily adapted to predict the response of the "3D" substructure defined in Figure 9. Accordingly, when a method will be available to predict the influence of the restraint provided by the upper storeys on the normal load in the column just above the failing one, it will be possible to predict analytically the behaviour of the global 3D structure through the substructure modelling.

\section{Dynamic behaviour of $2 \mathrm{~d}$ frames further to a column loss}

Comeliau et al. $(2009,2010)$ have studied the dynamic behaviour of 2D steel frames further to a column loss. In particular, a simplified model has been developed to predict the dynamic behaviour of the substructure defined in Section 2. Because of the limited allocation of pages, these works are not described in the present paper; for detailed information, the reader will refer to (Comeliau, 2009, 2010, 2012).

\section{Conclusions}

At Liège University, the exceptional scenario "loss of a column" in a building structure has been under investigation for a few years with the final objective to propose design requirements to ensure an appropriate robustness of structures under the considered scenario.

The present paper gives a global overview of the adopted development strategy for this scenario, of the achievements in this field so far and of the ongoing research activities. In particular, simplified analytical methods have been developed to predict the static response of 2D steel and composite frames further to a column loss. Investigations are presently in progress to extend these methods to 3D structures. Besides, the dynamic behaviour of 2D structures has been investigated and a procedure has been developed to predict the dynamic response of a simplified substructure. There further validation and there extension to 3D structures have still to be developed further. 


\section{References}

Comeliau L (2009). Effects of the dynamic behaviour of steel structures further to a column loss (in French)". Master thesis presented at Liège University, 2009 (freely downloadable at http://hdl.handle.net/2268/32284).

Comeliau L, Demonceau JF, Jaspart JP (2010). Robustness of steel and composite buildings under impact loading, Proceedings of SDSS Rio-2010 International Colloquium - Stability and Ductility of Steel Structures, Rio de Janeiro, pp. 393-400.

Comeliau L, Rossi B, Demonceau JF (2012). Robustness of steel and composite buildings suffering the dynamic loss of a column. Struct Eng Int, 22: 323-329.

Demonceau JF (2008). Steel and composite building frames: sway response under conventional loading and development of membrane effects in beams further to an exceptional action. $\mathrm{PhD}$ thesis presented at Liège University, (freely downloadable at http://orbi.ulg.ac.be/handle/2268/2740).

Demonceau JF, Jaspart JP (2010). Experimental test simulating a column loss in a composite frame. Adv Steel Constr, 6:891-913.

Huvelle C (2011). Contribution to the study of the robustness of building structures: progressive yielding of the indirectly affected part further to an exceptional event (in French), Master thesis presented at Liège University. (freely downloadable at http://orbi.ulg.ac.be/handle/2268/127083)

Kuhlmann U, Rolle L, Jaspart JP, Demonceau JF, Vassart O, Weynand K, Ziller C, Busse E, Lendering M, Zandonini R and Baldassino N (2008). Robust structures by joint ductility. Final report of the RFCS project N RFS-CR-04046.

Lemaire F (2010). Study of the 3D behaviour of steel and composite structures further to a column loss (in French)", Master thesis presented at Liège University.

Luu HNN (2008). Structural response of steel and composite building frames further to an impact leading to the loss of a column. PhD thesis presented at Liège University, 2008 (freely downloadable at http://bictel.ulg.ac.be/ETD-db/collection/available/ULgetd-01212009-095305/). 